\title{
ANCHOR-YIELD EXPOSED COLUMN BASES FOR MINIMIZING RESIDUAL DEFORMATIONS IN SEISMIC-RESISTANT STEEL MOMENT FRAMES
}

\section{Hiroyuki Inamasu¹, Albano de Castro e Sousa², Gerard Güell², and Dimitrios G. Lignos ${ }^{4}$,*}

${ }^{1}$ Doctoral Assistant, hiroyuki.inamasu@epfl.ch, École Polytechnique Fédérale de Lausanne (EPFL), GC B3 505, Station 18, Lausanne 1015, Switzerland

${ }^{2}$ Post-doctoral Researcher, albano.sousa@epfl.ch, École Polytechnique Fédérale de Lausanne (EPFL), GC B3 475, Station 18, Lausanne 1015, Switzerland

${ }^{3}$ Associate, guellgerard@hotmail.com, Swiss Re, Zurich, Switzerland

${ }^{4}$ Associate Professor (*corresponding author), dimitrios.lignos@epfl.ch, École Polytechnique Fédérale de Lausanne (EPFL), GC B3 485, Station 18, Lausanne 1015, Switzerland

This paper explores the concept of dissipative exposed column base connections by means of anchor rod yielding. This concept aims at enhancing the seismic performance of low-rise steel moment-resisting frames (MRFs). A mechanics-based model is proposed that explicitly simulates a broad range of damage mechanisms observed in exposed column bases. The model is implemented in a frame finite element analysis program and its hysteretic performance is validated with experimental data available in literature. Incorporating this modeling feature in standard nonlinear response history analyses offers new insights in steel MRF responses. It is shown that when low-rise steel MRFs adopt a dissipative anchor-yield column base concept, they are less likely to experience residual story drift ratios during low-probability of occurrence seismic events. It is also found that low-rise steel MRFs designed with non-dissipative exposed column base connections are more prone to demolition than dissipative ones, due to their higher column residual axial shortening, particularly when ground motion duration is an important feature of the seismic hazard. Limitations of the present work are also discussed.

\section{KEYWORDS}

Exposed column bases; Dissipative column base connections; Column axial shortening; Demolition; Steel momentresisting frames; Residual axial shortening hazard curves

\section{INTRODUCTION}

Non-dissipative steel column bases rely on a strong base/weak column design philosophy. This approach is intended to shift the inelastic rotation demand of the connection away from the foundation base connection onto the steel column immediately above it, whose flexural inelastic response is better understood. Relying solely on a member's flexural response may, however, bring unintended consequences. Recent experimental studies have shown that steel columns near the current limits of highly ductile members [1,2] are likely to experience a phenomenon known as axial shortening [3-6]. Figure 1 illustrates this instability mode from prior experimental work [7,8]. This phenomenon is characterized by the accumulation of residual axial displacements in a column under a combination of cyclic inelastic flexural and axial loading.

Axial shortening can come at significant economic cost. In a recent study, Elkady et al. [9] extended the loss estimation methodology proposed by Ramirez and Miranda [10] and found that in seismic regions where ground motions are characterized by long duration, steel column vertical residual deformations may control decisions regarding building demolition instead of residual story drift ratios [11,12]. This is also corroborated by field reconnaissance of first story steel MRF columns from the 2017 earthquake in Mexico [13,14]. Furthermore, while demolition may not strictly be needed from a safety perspective, refurbishment costs may be significant since axial shortening repairs remain challenging to perform [6]. A survey conducted by Elkady et al. [9] suggests that a limiting threshold for axial shortening that may trigger building demolition is, on average, $15 \mathrm{~mm}$. Considering that column axial shortening may evolve after a mainshock due to the gravitational load demand particularly if the local buckling is induced in the mainshock [14], repairs may be deemed necessary even if axial shortening is less than $15 \mathrm{~mm}$. Structural solutions that avoid or mitigate axial shortening will, therefore, assist reducing earthquake-induced losses. 
There are a number of solution strategies to address axial shortening. In a recent study, Inamasu et al. [15,16] found that the flexibility of the column base connection can reduce the associated inelastic deformation demand of the column, thus the amount of axial shortening. However, first story drift concentration is likely to occur in steel MRFs in this case [17]. Other studies have explored the weak-base/strong-column concept [18-20] as a potential alternative in steel MRF seismic design. The strategy rests on the idea that dissipation should be primarily located at the base and withdrawn from the column, potentially avoiding the shortening of the member. However, a coherent and/or complete methodology is lacking to implement this concept into the design practice.

The main focus of this paper is to advance the weak-base/strong-column concept for exposed column base connections (XCBs). The use of non-dissipative XCB connections is a common practice in low-rise seismic resistant steel frame buildings worldwide [21]. Figure 2 illustrates schematically a typical configuration of an XCB connection. It comprises a base plate, which is welded to a steel column, anchor rods that tie the base plate to a foundation, and the reinforced concrete foundation itself. A grout layer may be present between the foundation and the base plate. A shear lug is often attached to the base plate depending on the shear demand due to lateral loading. Depending on the column erection process leveling nuts may be used (see Fig. 2c). When designed to be fixed, the current design procedure of $\mathrm{XCB}$ connections requires them to be non-dissipative [2].

The seismic performance of XCBs has been thoroughly investigated in prior work [22-29]. Besides the wellestablished design procedures for XCB connections [21,30], the aforementioned studies highlighted that the overall behavior of XCBs is fairly complex due to the potential synergistic interaction of several components: (i) base plate, (ii) anchor rods, (iii) concrete foundation, (iv) anchor rod nuts (due to contact with the base plate and separation from the base plate), and (v) the presence of axial load demand. Nevertheless, it is acknowledged that XCBs can exhibit high inelastic rotation capacity when designed with a weak-base/strong-column concept. There are two main sources for a high weak-base/strong-column XCB rotation capacity: (1) anchor rod yielding [25,28] and (2) base plate yielding [31]. Anchor rod ductility is paramount to achieving high rotation capacities [22]. It is important to state that yielded anchor rods may be replaceable [28]. While the behavior of XCBs exhibiting base plate yielding is deemed to be ductile [31], this failure mode has not been fully explored. To further investigate the potential benefits of the above yield mechanisms, mechanics-based nonlinear models that capture full XCB hysteretic responses are lacking and should be developed.

Numerical models for XCBs that can be utilized in system-level simulations mostly employ point hinge models $[18,19,32]$. Because of their empirical nature, these models require a rigorous calibration to available physical component test results. A typical compromise of these models is that they neglect the axial load variation, which may be critical in end columns due to dynamic overturning effects. Tanaka et al. [23] proposed an alternative model in which each component of the XCB was explicitly modeled. However, this model disregarded a number of issues, such as (a) base plate deformations; (b) the presence of the leveling nuts; and (c) anchor rod cyclic hardening in the presence of leveling nuts. As such, the above modeling approach should be extended and made more general. Some of the aforementioned models have been successfully employed in system-level nonlinear building simulations $[17,19,23]$. These studies suggest that MRFs with non-dissipative bases may be vulnerable to first-story collapse mechanisms because of the inherent XCB flexibility.

In this paper, a mechanics-based numerical model is proposed for simulating the hysteretic behavior of exposed column base connections exhibiting various types of dissipative mechanisms at a reduced computational cost. The proposed model, which is made publicly available (https://doi.org/10.5281/zenodo.3958095), is suitable for systemlevel simulation studies. By means of simulation-based engineering a new dissipative XCB design concept is explored and proposed that promotes anchor rod yielding rather than the commonly used strong-base/weak-column philosophy. The potential benefits of the proposed concept are explored through nonlinear building simulations of 2-story steel MRFs. The simulation results are leveraged to develop novel axial shortening hazard curves to quantify the benefits of the proposed concept in the context of performance-based earthquake engineering. Limitations as well as concepts for future studies are also discussed.

\section{PROPOSED EXPOSED COLUMN BASE MODEL}

A parametrized two-dimensional (2-D) mechanics-based numerical model of XCBs, which is illustrated in Fig. 3, is developed in the Open System for Earthquake Engineering Simulation (OpenSees) platform [33]. The modeling approach integrates refined constitutive material laws to simulate a number of physical phenomena that may 
significantly influence the XCB's hysteretic behavior. The proposed model solely relies on material-level testing. Figure 3a illustrates an assumed deformed shape of an XCB. The primary assumptions of the proposed model are summarized as follows:

1. anchor rods are placed in one row per base plate side (see Figs. 2a and 3b),

2. the plastic deformation of the base plate is assumed to be fairly limited,

3. the grout layer and/or concrete foundation remains elastic under cyclic loading,

4. the shear load demand is fully transferred to the foundation without slip either by a shear lug or by friction between the base plate and the grout layer (or concrete).

The anchor rod modeling depends on the employed column erection procedure. In particular, the presence of leveling nuts changes the force transfer mechanism in XCB connections [25,27], thereby requiring a more refined modeling strategy. Referring to Figs. $3 \mathrm{~b}$ and c, anchor rods are modeled with a circular fiber section assigned to force-based beam-column elements [34] with five integration points. The Voce-Chaboche constitutive material law [35,36], which has been implemented in OpenSees [37] is assigned at each fiber to simulate the potential inelastic behavior of the base plate and the anchor rods. Prior experiments suggest that the bonding between anchors and the concrete foundation is generally negligible $[25,26,28]$. Therefore, it is assumed that the entire length of the anchor rod contributes to its axial deformation. Depending on the threading length (i.e., $h_{t h, 1}$ and $h_{t h, 2}$ in Figs. $2 \mathrm{~b}$ and $3 \mathrm{~b}$ ) or the presence of leveling nuts (see Fig. 2c), additional nonlinear segments should be used to further discretize the anchor rod length.

Referring to Fig. 3d (top), the slip behavior of the anchor rods is idealized with the Voce-Chaboche constitutive model in series with the rigid elastic no-compression law. This material is assigned to anchor rod elements in case of no leveling nuts (see Fig. 2d). This material is further combined in parallel with a rigid elastic no-tension material model to idealize the slip behavior when the strain demand is positive as well as the contact behavior when the strain demand is negative (i.e., contact with the leveling nuts) as shown in Fig. 3d (bottom). In case that leveling nuts are present, this material is assigned to an anchor rod element between the leveling nuts and the those at the top surface of the base plate while the Voce-Chaboche material is assigned to the rest of anchors. In all cases, the employed Voce-Chaboche material model is assigned a set of consistent input model parameters, which are derived for commonly used structural steels [38].

Referring to Figs. 2 and $3 \mathrm{~b}$, the minimum threaded, $D_{t h}$, and unthreaded, $D_{\text {unth }}$, diameters are adopted for the threaded and the unthreaded portions of the anchor rod, respectively. The base plate is modeled with a displacement-based beam-column element [39] that is assigned a fiber cross-section (outside the column depth) or an elastic beam-column element with an idealized rigid material (inside the column depth). The base plate is assumed to be rigid in between the two column flanges. Outside the column flanges, the Voce-Chaboche constitutive material model is employed. In the proposed modeling approach, the yield lines of the base plate are assumed to be perpendicular to the base plate length.

The grout and/or concrete foundation is modeled with truss elements (materializing so-called 'Winkler springs'). These are equally spaced along the base plate length. An elastic no-tension material model is employed for this purpose. As such, the potential column base uplifting under transient tensile load demands is explicitly considered. This is likely to occur in end columns of steel MRFs [40] due to dynamic overturning effects. The bearing stiffness of the foundation is determined as discussed in current standards [41,42]. Particularly, the axial bearing stiffness (i.e., axial force per unit displacement) of the foundation is estimated by assuming a rigid base plate in a half space as follows,

$K_{r b p}=\frac{E_{c} L_{b p}}{\alpha_{b p}}=\frac{E_{c} L_{b p}}{0.85 \sqrt{L_{b p} / B_{b p}}}$

where, $E_{c}$ is the elastic modulus of the concrete material, and $\alpha_{b p}$ is a factor dependent on the mechanical properties of the half space and is approximated by $0.85 \sqrt{L_{b p} / B_{b p}}$ according to Steenhuis et al. [41]. This value is distributed according to the tributary area of each Winkler spring. 
Vis-a-vis the above discussion, the proposed model can capture a range of physical phenomena, including the axial load - bending interaction, yielding of each XCB component, contact and slip behavior, as well as their synergistic interaction. The steel column above the XCB connection may be modeled with a point hinge model that is assigned the modified Ibarra-Medina-Krawinkler (IMK) model to acknowledge potential steel column cyclic deterioration in strength and stiffness in a strong base/weak column design philosophy. The parameters of this model may be based on Lignos et al. [43] for wide-flange steel columns and Lignos and Krawinkler [44] for hollow structural section (HSS) columns. If a weak base/strong column design is adopted, then a fiber-based modeling approach suffices.

\subsection{Proposed Model Validation}

The proposed model is validated with six available physical tests on XCBs with cantilever columns exhibiting various hysteretic behavior characteristics. In particular, the tests conducted by (1) Takamatsu and Tamai (2005) [45] (noted as specimens Fix-Ab-N=0C and Fix-Ab-N=0.1C); (2) Trautner et al. (2016) [27] (specimen S1S2); (3) Yamanishi et al. (2009) [24] (specimen S-Var); and (4) Gomez at al. (2010) [25] (specimens \#2 and \#5). Each simulation is performed with using a dynamic algorithm (i.e., quasi-static simulation) in order to stabilize the simulation with damping forces since the simulation can be unstable especially when stiffness changes abruptly.

Specimens Fix-Ab-N=0C and Fix-Ab-N=0.1C are both comprised of HSS200x200x12 columns (STKR400, nominal yield stress $f_{y}=245 \mathrm{MPa}$ ) welded to $400 \times 400 \times 50 \mathrm{~mm}$ steel base plates (SS400, $f_{y}=205-245 \mathrm{MPa}$ ). The base plates are tied with four rods (SNR400B, $f_{y}=215-355 \mathrm{MPa}$ ) (35 mm nominal diameter) on a stiff steel beam. Both specimens were subjected to lateral cyclic loading. A constant compressive axial load of $10 \%$ of the column yield axial resistance is applied to the second specimen in force control, while the first specimen's test is conducted with no axial force. The test specimens did not feature leveling nuts. The steel column and base plate were designed to remain elastic, whereas the anchor rods were designed to yield. The seven Winkler springs are assigned a rigid compressive stiffness because the foundation block of the test specimen involved a stiff steel beam. Stiffness proportional damping is applied to the Winkler springs as well as the anchor rod beam-column elements to improve the numerical stability of the proposed $\mathrm{XCB}$ model. To ensure an error-free numerical solution, the resultant damping forces within each rod were verified that remained less than $1 \%$ of the respective peak element force.

Figures $4 \mathrm{a}$ and $\mathrm{b}$ compare the simulated and measured base moment (i.e., moment acting at the base plate top surface level) versus column drift ratio (i.e., column top lateral displacement over the column height). Referring to Fig. 4a, since the anchor rods are the primary inelastic components of the XCB, its moment-rotation relation is governed by pinching. Yielding of the anchors is initiated in the threaded part and then spreads to the unthreaded part. Referring to Fig. 4b, the proposed model depicts the increase in the expected flexural strength of the XCB due to the presence of the compressive axial load. Slight differences in the flexural stiffness during the initial loading/unloading may be attributed to the flexibility of the steel beam foundation [45].

Referring to Fig. 4c, specimen S1S2 comprises a wide flange W8x48 steel column (ASTM A992 Gr. 50, $f_{y}=345$ MPa), four ASTM F1554 Gr. 36 ( $f_{y}=248 \mathrm{MPa}$ ) D19mm anchors (two anchors in each side) and a 460 x $460 \times 32 \mathrm{~mm}$ base plate made of ASTM A36 steel $\left(f_{y}=250 \mathrm{MPa}\right)$. The base plate, which is stiffened by plate stiffeners, rests on a grout layer on top of the concrete foundation. The specimen is subjected to cyclic lateral loading (in displacement control) without axial load. While for the most part, the numerical modeling approach is identical between this and the previous case, the axial stiffness of the Winkler springs is not rigid in this case. Referring to Eq. (1), the concrete bearing stiffness is based on the measured concrete material properties. Leveling nuts are not present in this case. Fig. $4 \mathrm{c}$ shows a close match between the simulation and experimental results. Therefore, the Winkler springs are deemed to represent reasonably well the bearing stiffness of the $\mathrm{RC}$ foundation.

In Fig. 4d, specimen S-Var comprises a HSS column (STKR400 200 x 200 x $12 \mathrm{~mm}$ ). The anchor rods are made of ABR400 $\left(f_{y}=215-355 \mathrm{MPa}\right)$ with two M16 anchors per side with $f_{y}=215-355 \mathrm{MPa}$. The $400 \times 400 \times 50 \mathrm{~mm}$ steel base plate is made of SS400. This rests on a rigid steel beam foundation. The specimen was subjected to reversed cyclic symmetric lateral loading (in displacement control) coupled with varying axial load demands in force control. The axial load was varied linearly with the base plate rotation. The specimen did not feature leveling nuts. Referring to Fig. 4d, the model captures well the transient axial load - moment interaction, which is an important characteristic of end columns in steel MRFs. Similarly to the previous test specimen, slight differences in the flexural stiffness of the XCB are attributed to the flexibility of the steel beam foundation [24]. 
Finally, specimens \#2 and \#5 consist of a wide flange W8x48 steel column (ASTM A992 Gr. 50), two ASTM F1554 Gr. $105\left(f_{y}=724 \mathrm{MPa}\right) \mathrm{D} 19 \mathrm{~mm}$ anchors per side and a $356 \times 356 \times 25.4 \mathrm{~mm}$ base plate made of A36 steel (i.e., $f_{y}=$ $250 \mathrm{MPa}$ ). The base plate rests on a grout layer on top of the concrete foundation, which is positioned flat with leveling nuts. The specimens were subjected to reversed cyclic symmetric lateral loading (in displacement control) coupled with a constant axial load of $411 \mathrm{kN}$. The anchor rods were designed to yield first followed by base plate yielding. Figures $4 \mathrm{e}$ and $4 \mathrm{f}$ compare the simulated and measured base moment-column drift ratios. Four different yielding mechanisms are evident in these tests, namely: (a) axial yielding and post-yield hardening of the threaded part as well as the shank (unthreaded part) of the anchor rods, which is similar to what was observed in specimens Fix-Ab-N $=0 \mathrm{C}$ and Fix-Ab-N=0.1C; (b) flexural yielding and post-yield hardening of the base plate; (c) pinching caused by the developed gap between the leveling and top nuts due to the plastic deformation of the corresponding anchor segments; and (d) an additional flexural resistance due to the axial load [25]. The interaction of the above yielding mechanisms results into a complex hysteretic behavior as shown in Figs. 4e and 4f. noteworthy stating that in Fig. 4e, while the model does not trace anchor rod fracture, it captures the overall hysteretic behavior of the XCB connection with an acceptable accuracy. Referring to Fig. 4f, the observed pinching is found to be strongly dependent on the amount of plastic deformation that is concentrated in between the leveling nuts, in the anchor segments below the leveling nuts and the base plate.

All-in-all, the proposed mechanics-based model is able to replicate the hysteretic behavior of XCBs exhibiting various yield mechanisms and their interaction without empirical calibrations to moment-rotation test data-- all calibrations are at the material and made for each XCB component. It is therefore reasonable to conclude that the proposed model is appropriate for system level studies to further examine the influence of anchor rod yielding on the overall steel MRF seismic performance.

\subsection{A Note on Parameter Sensitivity of the Proposed Model}

Having shown in Fig. 4 the ability of the proposed model to simulate different hysteretic behaviors due to a number of loading conditions and XCB configurations, a natural question arises: how sensitive are the model responses to its parameters? This information is useful to the modeler in order to decide which parameter should be thoroughly characterized when implementing the proposed modelling strategy. The question is addressed in detail by the authors in [46]. In brief, the influence of a number of parameters in the explicit XCB model performance are studied therein. Each of the following parameters is varied with each ratio $\alpha$ : (1) the number of Winkler springs on the base, $n_{W} ;$ (2) the stiffness of the Winkler springs, $\alpha_{\text {Winkler }} ;$ (3) the ratios of threaded to unthreaded areas of the anchor rods, $\alpha_{\text {unth }}$; (4) the ratios of threaded to total rod length, $\alpha_{h t h} ;(5)$ the ratios of the threaded levelling nut length to the total threaded length, $\alpha_{L N} ;(6)$ the magnitude of axial load, $\alpha_{P} ;(7)$ the initial yield stress, $\alpha_{\sigma y, 0}$; and (8) the secant plastic modulus (a work-hardening metric), $\alpha_{E s e c, r o d}$. Note that $n_{W}$ is replaced with the ratio $\alpha$ for (1). The influence of the parameters is judged by an error metric, represented by Eqs. 2 to 4, which traces the differences between the moments in a perturbed model to a reference model throughout loading - similarly to the metrics proposed in de Castro e Sousa et al. [38]. The perturbed model is characterized by changes in each of the aforementioned parameters (around 10 to 20 $\%$ for most variables), and sensitivity is defined by the change in the error metric with respect to a unit change of the parameter under study - Eq. 5. Figure 5 shows tornado plots that compare the relative weight of each factor on the moment - rotation curve of the XCB with the sensitivity metric $\xi$ in two characteristic specimens.

$$
\begin{aligned}
& \theta_{\text {accum }}=\int_{0}^{t}|\dot{\theta}| d \tau \\
& \phi=\frac{\int_{0}^{\theta_{\text {accum }}\left[M_{\alpha}(\bar{\theta})-M_{r e f}(\bar{\theta})\right]^{2} d \bar{\theta}}}{\int_{0}^{\theta \text { accum } d \bar{\theta}}} \\
& \bar{\phi}=\sqrt{\frac{\phi}{\frac{\int_{0}^{\theta \text { accum }}\left[M_{\text {ref }}(\bar{\theta})\right]^{2} d \bar{\theta}}{\int_{0}^{\theta \text { accum }} d \bar{\theta}}}} \\
& \xi=\Delta \bar{\phi} / \Delta \alpha
\end{aligned}
$$


In which, $\theta_{\text {accum }}$ is the accumulated column drift ratio, $\theta$ in this case; $M_{a}$ is the simulated moment of the perturbated model; $M_{\text {ref }}$ is the moment of the reference model used herein for a given drift ratio loading history $\theta$. The conclusions of the sensitivity study indicate that the hysteretic response of XCBs is influenced the most by the ratio between the threaded and unthreaded anchor rod areas. Other variables that significantly influence the XCB response in descending order are (i) the initial yield stress of the anchor rod, (ii) when present, the ratio of threaded length of the levelling nut to the total threaded length, (iii) the axial load of the member, and, to a lesser extent, (iv) the secant plastic modulus of the anchor rods' material. The ratio of threaded anchor rod length-to-total rod length does not appear to significantly affect explicit XCB responses. At the foundation level, it is also concluded that the number of Winkler springs and their stiffness have a negligible weight on the model response.

\section{SEISMIC DESIGN OF STEEL MOMENT-RESISTING FRAMES WITH DISSIPATIVE AND NON- DISSIPATIVE EXPOSED COLUMN BASES}

Three two story perimeter steel MRF buildings are designed to explore the potential benefits of dissipative XCBs at the system level and compare those with the behavior of steel MRFs designed with non-dissipative fixed bases:

- Case 1: conventional fixed bases (non-dissipative);

- Case 2: exposed column bases designed to remain elastic by considering the column base flexibility;

- Case 3: exposed column bases deliberately designed to exhibit anchor rod yielding prior to steel column yielding (i.e., weak-base/strong-column concept).

The building plan view, which is consistent with prior studies [47,48], is shown in Fig. 6. Each MRF, which is designed according to the current US practice [2,49-51] has three bays with a span of $6.1 \mathrm{~m}$ and fully restrained beam-tocolumn connections with reduced beam sections (RBS). The building is located in urban California (seismic design category D, site class D) (Coordinates: $\left.33.996^{\circ} \mathrm{N}, 118.162^{\circ} \mathrm{W}\right)$. Beams and columns are designed with ASTM A992 Gr. 50 (i.e., $\left.f_{y}=345 \mathrm{MPa}\right)$ steel. The XCBs feature ASTM F1554 Gr. $105\left(f_{y}=724 \mathrm{MPa}\right)$ fully threaded anchor rods, an ASTM A572 Gr. $50\left(f_{y}=345 \mathrm{MPa}\right)$ base plate, and concrete footings with a specified compressive strength of $30 \mathrm{MPa}$. Leveling nuts are not used. Reinforcements in the foundation are also considered to prevent potential coneshape break out failure.

In Case 3, the XCBs are designed to exhibit anchor rod yielding at a moment equal to the yield moment of the columns in the MRF with fixed bases. Thus, in the first design iteration, the anchors are sized to achieve the expected yield moment of the first story columns in the MRF with fixed bases. The base plate, and reinforced concrete/grout foundation are designed to remain elastic until the anchors reach their ultimate axial strength. Once the XCB dimensions are determined, the column cross sections are increased such that they remain elastic up until the XCBs reach their ultimate flexural strength.

The steel MRF designs are summarized in Table 1. Figure 7 shows the final designs for Cases 2 and 3. Interestingly, the anchor rod yielding concept leads to a thinner base plate compared to the conventional one.

\section{NONLINEAR BUILDING MODELS}

Two dimensional numerical models of the steel MRFs in the East-West loading direction are developed in OpenSees. Steel beams and columns are modeled with elastic beam-column elements with point hinge deterioration models based on the modeling recommendations by Lignos et al. [43,52]. The panel zones are modeled explicitly as discussed in [53]. The gravity framing is also considered as discussed in Elkady and Lignos [47]. In Cases 2 and 3, the column bases are modeled with the proposed XCB model.

Rayleigh damping with a $2 \%$ damping ratio is assigned at the first and second modes of each steel MRF as discussed in [54]. Eigenvalue analysis of each structure indicates that the first mode natural periods, $T_{1}$, of the steel MRFs are $0.66,0.64$, and 0.60 s for Cases 1,2 and 3, respectively.

\section{GROUND MOTIONS AND SITE-SPECIFIC HAZARD CURVE}


For the seismic performance evaluation of the three MRFs, spectrally matching short duration (SD) and long duration (LD) ground motion sets originally employed in the study of [55] are used. In brief, each ground motion set contains 146 ground motions. Each ground motion set is adjusted to the design-basis earthquake (DBE) intensity (i.e., $10 \%$ exceedance in 50 years) and the maximum considered earthquake (MCE) intensity (i.e., $2 \%$ exceedance in 50 years) based on the acceleration spectrum of the design location. The average spectral acceleration, $S a_{\text {avg }}[56]$ is used as an intensity measure (IM) for the ground motion scaling. Each record is scaled such that $S a_{a v g}$ is computed over $0.2 T_{1}$ to $3.0 T_{1}$ be the same between the target and the 5\% critical damping elastic response spectrum of each ground motion.

For the design site, probabilistic seismic hazard analysis is also performed for the average spectral acceleration, $S a_{a v g}$. The United States Geological Survey (USGS) 2008 source model [57] is adopted by accounting for all fault sources within $200 \mathrm{~km}$ from the site. OpenQuake (version 3.7.1) [58] is used to perform the seismic hazard computations. In the hazard analysis, $S a_{a v g}$ is defined as the geometric mean of spectral accelerations in the period range of [0.2 2.0]s discretized in increments of $0.1 \mathrm{~s}$, to be consistent with the $S a_{\text {avg }}$ definition used in the ground motion scaling. The obtained $S a_{\text {avg }}$ hazard curve is shown in Fig. 8.

\section{NONLINEAR RESPONSE HISTORY ANALYSIS}

Nonlinear response history analysis of the three steel MRFs is performed with both ground motion sets at the DBE and MCE seismic intensities. Of interest are the global engineering demand parameters (EDPs) such as the peak and residual story drift ratios (SDRs). In terms of local EDPs, the focus is on column residual axial shortening. The median of the local and global EDPs is employed to facilitate the subsequent discussion.

Figure 9 shows the effect of the column base design (i.e., Fixed base, Elastic base, Dissipative base by means of anchor yielding) on the median EDPs of interest for the two ground motion sets (left: short duration; right: long duration). Referring to Fig. 9a, the results in terms of peak SDRs are fairly similar regardless of the steel MRF design for a given ground motion intensity. Interestingly, peak SDR demands along the steel MRF heights, for the short duration set, are slightly larger than those from the spectrally matched long duration set. The amplitude of the lateral drift demand of a building is largely dependent on pulses contained in the ground motion characteristics that could cause a large incremental velocity $[59,60]$ as well as the initial conditions of the building (drift, floor velocity and their directions) when these pulses act on the building [61]. Herein, the incremental velocity prior to the peak first story drift ratio response is computed for both ground motion sets. It is found that there is a relatively high correlation coefficient (i.e., 0.70 ) between the incremental velocity and the peak first story drift demand. The incremental velocity is found to be $15 \%$ larger in the SD set compared to that of the LD set.

For the same reason discussed earlier, the median residual SDRs along the height of the three steel MRFs is $50 \%$ larger for the SD set (see Fig. 9b left) than the corresponding one from the LD set (see Fig. 9b right). However, in all cases, there are no distinct differences in the residual SDRs between the three designs; hence, neither the column base flexibility (Case 2) nor the dissipative column bases (Case 3) alter the seismic behavior of low-rise steel MRFs as compared to the conventional design case (i.e., Case 1).

Figures 9c depicts the median column axial shortening of the first story interior column for the three steel MRF designs for both ground motion sets, respectively. During the 475-year seismic event (DBE) an ideally fixed end column does not experience, on average, more than $5 \mathrm{~mm}$ axial shortening. This is about $50 \%$ less when the inherent column base flexibility is acknowledged. This agrees with component level studies on embedded column base connections [16].

At seismic intensities associated with a low probability of occurrence seismic event (i.e., MCE), axial shortening does not seem to be a major concern, for the examined cases, when the ground motion history does not exhibit long duration characteristics (see Fig. 9c left). On the other hand, conventional fixed end columns with non-dissipative bases may exhibit, on average, $15 \mathrm{~mm}$ to $30 \mathrm{~mm}$ axial shortening under long duration ground motions (see Fig. 9c right). From a reparability standpoint, this is a major challenge to be addressed in slender, but still seismically compact, steel column profiles. The reserve capacity of these members may also be a fundamental concern [6]. Referring to Fig. 9c, the steel MRF with dissipative bases does not experience any axial shortening regardless of the ground motion characteristics and the seismic intensity. 
The above comparisons suggest that column base flexibility is somewhat beneficial in reducing column axial shortening. However, this may be completely eliminated when employing dissipative column base connections in the seismic design process of steel MRFs. As mentioned previously, the justification for the previous statement is related to a shift of the dissipation mechanism from the column to the connection at its base. Figure 10 depicts representative comparisons of the column base moment-rotation response of the first story interior column in all three designs for a characteristic long duration ground motion (1974 Lima Peru Earthquake recorded at Arequipa station), which is scaled at the MCE intensity. Referring to Fig. 10a, which compares the ideally fixed versus the flexible base, although the moment - rotation is governed by the inelastic rotation of the column, the elastic contribution of the column base reduces the amount of column axial shortening. Conversely, when the dissipative column base concept is employed (see Fig. 10b), the plastic hinge in the column base is fully shifted from the column bottom to the XCB connection, thereby eliminating the inelastic rotational demands of the steel column. Consequently, the column axial shortening, which is strongly correlated with the inelastic cumulative damage of the steel column $[62,63]$, is zero. Same findings hold true for end columns.

\section{COLUMN AXIAL SHORTENING HAZARD CURVE AND ANNUALIZED PROBABILITIES OF EXCEEDANCE}

In order to quantify the significance of column axial shortening in the context of performance-based design of lowrise steel MRF buildings, an axial shortening hazard curve is developed for the three steel MRF designs. While EDP hazard curves have been developed in prior studies [64-66], the primary emphasis was on peak SDRs and peak absolute floor accelerations. The column axial shortening hazard curve can be an effective tool to quantify the annualized column axial shortening depending on the employed seismic design at key return periods of interest to the engineering profession. To put things into perspective, a residual SDR hazard curve is also developed for the three case studies discussed earlier. The EDP hazard curves presented hereinafter are developed based on the methodology outlined in detail in Krawinkler et al. [67].

Figure 11 shows comparisons of the probabilities of exceedance of each one of the two EDPs of interest per ground motion set. For each case, a log-normal distribution is assumed to reasonably represent the simulated building response data. These plots provide the dispersion of each EDP in addition to the medians. Referring to Fig. 11a, the exceedance functions (i.e., one minus cumulative distribution function) for residual SDRs are nearly identical for the ideally fixed and flexible base case regardless of the ground motion characteristics and the seismic intensity of interest. Interestingly, the 2-story steel MRF with dissipative bases is generally less likely to experience residual SDRs both at DBE and MCE seismic intensities, than its fixed base counterpart, which is consistent with prior observations from shake table testing [20].

Similarly, Fig. 11b depicts the exceedance functions for the column axial shortening of the examined two story steel MRFs designed with ideally fixed and flexible bases. Results for the steel MRF with dissipative bases are not presented because axial shortening in this case is zero regardless of the seismic intensity. Referring to Fig. 11b, for ground motions that do not feature duration characteristics (left), column axial shortening is less likely to develop. There is at least a $70 \%$ chance for the two-story steel MRF with ideally fixed bases to experience $20 \mathrm{~mm}$ of axial shortening at MCE during a long duration earthquake record (right). This is discounted to at least $40 \%$ when the inherent flexibility of the column base is considered in the seismic response of the two-story steel MRF.

The exceedance functions discussed earlier facilitate the development of EDP hazard curves to further interpret the aforementioned findings within a performance-based design context. These curves are developed by employing the results from the double-stripe nonlinear response history analyses of the three steel MRFs as discussed in [68]. Specifically, the median relationship of EDP - IM is approximated with a power function. The dispersion of the natural logarithm of EDP given IM is assumed to be constant, which is a common assumption $[67,69]$. The corresponding EDP hazard curves $\lambda_{E D P}(y)$ are then obtained according to Eq. (6),

$\lambda_{E D P}(y)=\int P[E D P \geq y \mid I M=x]\left|d \lambda_{I M}(x)\right|$

where $P[E D P \geq y \mid I M=x]$ is the probability of the EDP exceeding $y$ given that IM is equal to $x$; and $\lambda_{I M}(x)$ is the IM hazard curve, which was derived in Fig. 8. Numerical integration is employed herein to compute $\lambda_{E D P}(y)$. The EDP hazard curves for residual SDRs and the column axial shortening are shown in Fig. 12. The annual rates of 
exceedance of targeted EDPs corresponding to three characteristic return periods (i.e., 72 years, 475 years and 2475 years) are superimposed in the same figures (horizontal dashed lines). These are computed by assuming that earthquakes follow a Poisson distribution. The deduced values, in terms of the expected residual SDRs and column axial shortening for the steel MRF designs, are summarized in Table 2.

Referring to the annual rate corresponding to the probability of exceedance of $2 \%$ in 50 years (2475 years return period), the residual SDR is about $0.6 \%$ in all cases for the SD ground motion set, which is deemed acceptable [70]. When the ground motion set depicts long duration characteristics, then the two story steel MRF with dissipative bases is less likely to experience residual story drifts for the 2475 year seismic event, which is consistent with shake table experiments on idealized structures with dissipative bases [20].

For the same annual rate of exceedance (i.e., 2475-year return period), the developed axial shortening hazard curves suggest that the column axial shortening is $15 \mathrm{~mm}$ (fixed base) and $7 \mathrm{~mm}$ (flexible base) when duration is a key ground motion characteristic. Recent studies [6] found that depending on the level of the imposed compressive axial load and column cross section local slenderness, a 10 to $15 \mathrm{~mm}$ axial shortening may be challenging from a reparability standpoint and may cause appreciable downtime in the aftermath of earthquakes. Other concerns with regard to vertical collapse mechanisms should be examined by means of system-level simulations. This is corroborated by a recent field reconnaissance of the 2017 Mexico earthquake [14] in a low rise steel MRF in which the axial shortening of its first story columns, which featured seismically compact cross sections, considerably evolved in a mainshock-aftershock earthquake series due to the gravitational load demand. Particularly, the column was completely squashed 51 days after the mainshock event. Referring to Table 2, it is noteworthy stating that column axial shortening does not occur when dissipative column base connections are employed in steel MRFs.

\section{LIMITATIONS}

The present study features a number of limitations. Particularly, the proposed XCB model does not consider fracture initiation in the anchor rods. However, back calculations with the proposed model from experiments [23,25,27] suggest that anchor rods can sustain more than $10 \%$ inelastic strain demands in the threaded length prior to fracture. While in the present study this threshold was never exceeded (i.e., $5 \%$ tensile strain demand at maximum), this may be a critical consideration in other steel MRF configurations that were not examined herein.

The proposed model is applicable for 2-D nonlinear response history analysis. Three dimensional effects due to bidirectional loading have not been addressed. The proposed model is not applicable for column bases in which the base plates and/or the concrete footing experience appreciable inelastic deformations. In the former, the yield lines of the base plate may not necessarily be perpendicular to the lateral loading direction.

\section{SUMMARY AND CONCLUSIONS}

This paper proposes an explicit mechanics-based model for simulating various damage mechanisms observed in exposed column base connections as part of steel moment-resisting frames designed in seismic regions. The model requires only material level data to derive consistent input parameters for nonlinear analysis of exposed column base connections, thereby reducing the need for component and/or subassembly tests. Through validations with a broad range of available experiments in the literature, it is found that the proposed model is able to simulate, among other damage mechanisms, anchor rod yielding, the axial load-bending interaction as well as the influence of axial load variation on the column base response. Moreover, the proposed model traces the characteristic pinching behavior of the base when leveling nuts are present for positioning the column vertically. The governing parameters on the cyclic behavior of exposed column bases are the initial yield stress of the anchor rods, the ratio of threaded length of the leveling nut, when present, to the total threaded length of the anchor rods, as well as the axial load demand. The influence of the secant plastic modulus of the anchor rod's material on the overall column base behavior is fairly minor. It is found that when anchor rod yielding is promoted, the column base behavior is stable to large inelastic drift demands provided that ductile anchors are considered in the column base design. As such, a designer should decide the relative strength of the anchor rods with respect to the base plate, steel column or concrete foundation according to the yield mechanism that should be favored, which, in this case, is anchor rod yielding. If this is known a priori, a simpler point hinge phenomenological model may be used for system-level nonlinear analyses. The proposed model 
is a valuable alternative to computationally demanding continuum finite element models of exposed column bases when the objective is to explore their hysteretic behavior depending on the anticipated yield mechanism.

System level nonlinear building simulations of three characteristic boundary condition cases suggest that low-rise steel MRFs with dissipative exposed column base connections are less likely to experience residual story drift ratios than their conventional fixed base counterparts under low probability of occurrence subduction zone earthquakes. Through the development of novel column axial shortening hazard curves it is shown that, when duration is an important ground motion feature, the expected column axial shortening may be a critical consideration in low-rise steel MRFs from a reparability and building demolition standpoint because it attains, on average, $15 \mathrm{~mm}$ for the 2475year seismic event. However, it was shown that low-rise steel MRFs in which anchor rod yielding is promoted do not experience column axial shortening at all, thus avoiding the issue entirely. A number of limitations with regard to the present work were also presented that highlight the need for future work.

\section{ACKNOWLEDGMENTS}

This study is based on work supported by the Swiss National Science Foundation (Award No. 200021_169248). Financial support for the second author was also provided through an internal EPFL funding as well as SNSF Spark (Award No. 200021_190535). The financial support is gratefully acknowledged. The authors would like to sincerely thank Dr. Mohsen Kohrangi of University School for Advanced Studies IUSS (Pavia, Italy) for developing the $S a_{a v g}$ hazard curve used in this study. The authors would also like to extend their appreciation to Prof. Reagan Chandramohan of University of Canterbury, and Profs. Jack W. Baker and Gregory G. Deierlein of Stanford University who shared the two ground motion sets used in this study. Any opinions, findings, and conclusions or recommendations expressed in this paper are those of the authors and do not necessarily reflect the views of sponsors.

\section{DATA AVAILABILITY STATEMENT}

Source code used to develop the proposed model for simulating the response of exposed column base connections including some of the presented examples is available at https://doi.org/10.5281/zenodo.3958095. The authors hope that the source code will help interested readers to perform further investigations of the proposed design concept and will also provide documented improvements of the proposed model for system-level building simulations.

\section{REFERENCES}

1. AIJ. Recommendation for limit state design of steel structures, third edition. Architectural Institute of Japan; 2010.

2. AISC. Seismic provisions for structural steel buildings. ANSI/AISC 341-16. American Institute of Steel Construction; 2016.

3. Suzuki Y, Lignos DG. Large scale collapse experiments of wide flange steel beam-columns. Proceedings of the 8th International Conference on Behavior of Steel Structures in Seismic Areas (STESSA), Shanghai, China: 2015.

4. Ozkula G, Harris J, Uang CM. Observations from cyclic tests on deep, wide-flange beam-columns. Engineering Journal 2017; 1: 45-59.

5. Elkady A, Lignos DG. Full-scale testing of deep wide-flange steel columns under multiaxis cyclic loading: Loading sequence, boundary effects, and lateral stability bracing force demands. Journal of Structural Engineering 2018; 144(2): 04017189. DOI: 10.1061/(ASCE)ST.1943-541X.0001937.

6. Cravero J, Elkady A, Lignos DG. Experimental evaluation and numerical modeling of wide-flange steel columns subjected to constant and variable axial load coupled with lateral drift demands. Journal of Structural Engineering 2020; 146(3): 04019222. DOI: 10.1061/(ASCE)ST.1943-541X.0002499.

7. Suzuki Y. Earthquake-induced collapse of steel moment resisting frames with conventional and high performance steel columns. PhD Thesis. McGill University, Montreal, 2019.

8. Suzuki Y, Lignos DG. Experimental investigation of steel columns under seismic hazard-consistent collapse loading protocols (under review). Journal of Structural Engineering 2020.

9. Elkady A, Güell G, Lignos DG. Proposed methodology for building-specific earthquake loss assessment including column residual axial shortening. Earthquake Engineering \& Structural Dynamics 2020; 49(4): 339355. DOI: $10.1002 /$ eqe.3242.

10. Ramirez CM, Miranda E. Significance of residual drifts in building earthquake loss estimation. Earthquake Engineering \& Structural Dynamics 2012; 41(11): 1477-1493. DOI: 10.1002/eqe.2217. 
11. Clifton GC, Bruneau M, MacRae GA, Leon R, Fussell A. Steel structures damage from the Christchurch earthquake series of 2010 and 2011. Bulletin of the New Zealand Society for Earthquake Engineering 2011; 44(4): 297-318.

12. MacRae GA, Clifton GC, Bruneau M, Kanvinde AM, Gardiner S. Lessons from steel structures in Christchurch earthquakes. 8th International Conference on Behavior of Steel Structures in Seismic Areas (STESSA), Shanghai, China 2015: 1474-1481.

13. Galvis F, Miranda E, Heresi P, Davalos H, Silos JR. Preliminary statistics of collapsed buildings in Mexico City in the September 19, 2017 Puebla-Morelos Earthquake. 2017.

14. Tapia-Hernández E, García-Carrera JS. Damage assessment and seismic behavior of steel buildings during the Mexico earthquake of 19 September 2017. Earthquake Spectra 2020; 36(1): 250-270.

15. Inamasu H, Lignos DG, Kanvinde AM. Influence of embedded steel column base strength on earthquake-induced residual deformations. Proceedings of 16th European Conference on Earthquake Engineering, 16th European Conference on Earthquake Engineering. Thessaloniki, Greece: 2018.

16. Inamasu H, Kanvinde AM, Lignos DG. Seismic stability of wide-flange steel columns interacting with embedded column base connections. Journal of Structural Engineering 2019; 145(12): 04019151. DOI: 10.1061/(ASCE)ST.1943-541X.0002410.

17. Zareian F, Kanvinde A. Effect of column-base flexibility on the seismic response and safety of steel momentresisting frames. Earthquake Spectra 2013; 29(4): 1537-1559.

18. Lignos DG, Hikino T, Matsuoka Y, Nakashima M. Collapse assessment of steel moment frames based on EDefense full-scale shake table collapse tests. Journal of Structural Engineering 2013; 139(1): 120-132. DOI: 10.1061/(ASCE)ST.1943-541X.0000608.

19. Cui Y, Wang F, Yamada S. Effect of column base behavior on seismic performance of multi-story steel moment resisting frames. International Journal of Structural Stability and Dynamics 2019; 19(01): 1940007. DOI: $10.1142 / \mathrm{S} 0219455419400078$.

20. Trautner C, Hutchinson T, Grosser P, Piccinin R, Silva J. Shake table testing of a miniature steel building with ductile-anchor, uplifting-column base connections for improved seismic performance. Earthquake Engineering \& Structural Dynamics 2019; 48(2): 173-187. DOI: 10.1002/eqe.3130.

21. Fisher J, Kloiber L. Base plate and anchor rod design, steel design guide 1, 2nd edition 2006.

22. Grauvilardell JE, Lee D, Hajjar JF, Dexter RJ. Synthesis of design, testing and analysis research on steel column base plate connections in high-seismic zones 2005.

23. Tanaka H, Mitani I, Shimamura Y, Itoh M. Elasto-plastic behavior of steel frame with exposed type column base subjected to variable axial force. Steel Construction Engineering (In Japanese) 2005; 12(45): 171-184. DOI: https://doi.org/10.11273/jssc1994.12.171.

24. Yamanishi T, Takamatsu T, Tamai H, Matsumura T, Matsuo A. Resistance mechanism of non-slip-type exposed column-base under tensile variable axial-force. Journal of Structural and Construction Engineering (Transactions of AIJ) (In Japanese) 2009; 74(642): 1495-1502. DOI: https://doi.org/10.3130/aijs.74.1495.

25. Gomez I, Deierlein G, Kanvinde A. Exposed column base connections subjected to axial compression and flexure. Final Report Presented to American Institute of Steel Construction. Chicago: 2010.

26. Kanvinde AM, Jordan SJ, Cooke RJ. Exposed column base plate connections in moment frames - simulations and behavioral insights. Journal of Constructional Steel Research 2013; 84: 82-93. DOI: 10.1016/j.jcsr.2013.02.015.

27. Trautner CA, Hutchinson Tara C., Grosser PR, Silva JF. Effects of detailing on the cyclic behavior of steel baseplate connections designed to promote anchor yielding. Journal of Structural Engineering 2016; 142(2): 04015117. DOI: 10.1061/(ASCE)ST.1943-541X.0001361.

28. Trautner CA, Hutchinson T, Grosser PR, Silva JF. Investigation of steel column-baseplate connection details incorporating ductile anchors. Journal of Structural Engineering 2017; 143(8): 04017074. DOI: 10.1061/(ASCE)ST.1943-541X.0001759.

29. Trautner CA, Hutchinson TC. Parametric finite-element modeling for exposed steel moment frame column baseplate connections subjected to lateral loads. Journal of Structural Engineering 2018; 144(6): 04018049. DOI: 10.1061/(ASCE)ST.1943-541X.0001990.

30. Kanvinde AM, Grilli D, Zareian F. Rotational stiffness of exposed column base connections: experiments and analytical models. Journal of Structural Engineering 2012; 138(5): 549-560. DOI: 10.1061/(ASCE)ST.1943541X.0000495.

31. Burda JJ, Itani AM. Studies on seismic behavior of steel base plates. University of Nevada; 1999.

32. Rodas PT, Zareian F, Kanvinde A. Hysteretic model for exposed column-base connections. Journal of Structural Engineering 2016; 142(12): 04016137. 
33. McKenna F. Object oriented finite element programming frameworks for analysis, algorithms and parallel computing. Ph.D. Thesis. University of California, Berkeley, 1997.

34. Neuenhofer A, Filippou FC. Evaluation of nonlinear frame finite-element models. Journal of Structural Engineering 1997; 123(7): 958-966. DOI: 10.1061/(ASCE)0733-9445(1997)123:7(958).

35. Voce E. The Relationship between stress and strain for homogeneous deformation. Journal of the Institute of Metals 1948; 74: 537-562.

36. Chaboche JL, Van KD, Cordier G. Modelization of the strain memory effect on the cyclic hardening of 316 stainless steel. The 5th International Conference on SMiRT, vol. L11, The 5th International Conference on SMiRT. Berlin: IASMiRT; 1979.

37. Hartloper AR, de Castro e Sousa A, Lignos DG. Constitutive modeling of structural steels: a nonlinear isotropic/kinematic hardening material model and its calibration (under review). Journal of Structural Engineering 2020.

38. de Castro e Sousa A, Suzuki Y, Lignos DG. Consistency in solving the inverse problem of the Voce-Chaboche constitutive model for plastic straining. Journal of Engineering Mechanics 2020; 146(9): 04020097. DOI: 10.1061/(ASCE)EM.1943-7889.0001839.

39. Zeris CA, Mahin SA. Analysis of reinforced concrete beam-columns under uniaxial excitation. Journal of Structural Engineering 1988; 114(4): 804-820. DOI: 10.1061/(ASCE)0733-9445(1988)114:4(804).

40. Suzuki Y, Lignos DG. Development of collapse-consistent loading protocols for experimental testing of steel columns. Earthquake Engineering \& Structural Dynamics 2020; 49(2). DOI: 10.1002/eqe.3225.

41. Steenhuis CM, Wald F, Stark JWB, Sokol Z, Taylor JC. Resistance and stiffness of concrete in compression and base plate in bending. JCSR in Printing 2000.

42. CEN. Eurocode 3 design of steel structures part 1-8: design of joints 2005.

43. Lignos DG, Hartloper AR, Elkady A, Deierlein GG, Hamburger R. Proposed updates to the ASCE 41 nonlinear modeling parameters for wide-flange steel columns in support of performance-based seismic engineering. Journal of Structural Engineering 2019; 145(9): 04019083. DOI: 10.1061/(ASCE)ST.1943-541X.0002353.

44. Lignos DG, Krawinkler H. A steel database for component deterioration of tubular hollow square steel columns under varying axial load for collapse assessment of steel structures under earthquakes. Proc. 7th Int. Conf. on Urban Earthquake Engineering (7CUEE), Center for Urban Earthquake Engineering, Tokyo Institute of Technology Tokyo; 2010.

45. Takamatsu T, Tamai H. Non-slip-type restoring force characteristics of an exposed-type column base. Journal of Constructional Steel Research 2005; 61(7): 942-961.

46. de Castro e Sousa A, Inamasu H, Lignos DG. An explicit model for exposed column base connections and its parameter sensitivity. Proceedings of 12th Pacific Structural Steel Conference, 12th Pacific Structural Steel Conference. Tokyo, Japan: 2019.

47. Elkady A, Lignos DG. Effect of gravity framing on the overstrength and collapse capacity of steel frame buildings with perimeter special moment frames. Earthquake Engineering \& Structural Dynamics 2015; 44(8): 1289-1307. DOI: 10.1002 /eqe.2519.

48. NIST. Evaluation of the FEMA P695 methodology for quantification of building seismic performance factors. NEHRP consultations Joint Venture; 2010.

49. AISC. Specification for structural steel buildings. ANSI/AISC 360-16. American Institute of Steel Construction; 2016.

50. AISC. Prequalified connections for special and intermediate steel moment frames for seismic applications. ANSI/AISC 358-16. American Institute of Steel Construction; 2016.

51. ASCE. Minimum design loads and associated criteria for buildings and other structures. ASCE/SEI 7-16. American Society of Civil Engineers; 2016.

52. Lignos DG, Krawinkler H. Deterioration modeling of steel components in support of collapse prediction of steel moment frames under earthquake loading. Journal of Structural Engineering 2011; 137(11): 1291-1302. DOI: 10.1061/(ASCE)ST.1943-541X.0000376.

53. Gupta A, Krawinkler H. Seismic demands for the performance evaluation of steel moment resisting frame structures. Ph.D. Thesis. Stanford University, 1998.

54. Zareian F, Medina RA. A practical method for proper modeling of structural damping in inelastic plane structural systems. Computers \& Structures 2010; 88(1): 45-53. DOI: 10.1016/j.compstruc.2009.08.001.

55. Chandramohan R, Baker JW, Deierlein GG. Quantifying the influence of ground motion duration on structural collapse capacity using spectrally equivalent records. Earthquake Spectra 2015; 32(2): 927-950. DOI: 10.1193/122813EQS298MR2. 
56. Eads L, Miranda E, Lignos DG. Average spectral acceleration as an intensity measure for collapse risk assessment. Earthquake Engineering \& Structural Dynamics 2015; 44(12): 2057-2073. DOI: 10.1002/eqe.2575.

57. Petersen MD, Frankel AD, Harmsen SC, Mueller CS, Haller KM, Wheeler RL, et al. Documentation for the 2008 update of the United States national seismic hazard maps. US Geological Survey; 2008.

58. Pagani M, Monelli D, Weatherill G, Danciu L, Crowley H, Silva V, et al. OpenQuake engine: An open hazard (and risk) software for the global earthquake model. Seismological Research Letters 2014; 85(3): 692-702.

59. Bertero VV, Mahin SA, Herrera RA. Aseismic design implications of near-fault san fernando earthquake records. Earthquake Engineering \& Structural Dynamics 1978; 6(1): 31-42. DOI: 10.1002/eqe.4290060105.

60. Dávalos H, Miranda E. Filtered incremental velocity: A novel approach in intensity measures for seismic collapse estimation. Earthquake Engineering \& Structural Dynamics 2019; 48(12): 1384-1405. DOI: 10.1002/eqe.3205.

61. Eads L. Seismic collapse risk assessment of buildings: effects of intensity measure selection and computational approach. PhD Thesis. Stanford University, 2013.

62. Elkady A, Lignos DG. Improved seismic design and nonlinear modeling recommendations for wide-flange steel columns. Journal of Structural Engineering 2018; 144(9): 04018162. DOI: 10.1061/(ASCE)ST.1943541X.0002166.

63. MacRae GA, Carr AJ, Walpole WR. The seismic response of steel frames. Christchurch, New Zealand: Department of Civil Engineering, University of Canterbury; 1990.

64. Medina RA, Krawinkler H. Seismic demands for nondeteriorating frame structures and their dependence on ground motions. Pacific Earthquake Engineering Research Center Berkeley; 2004.

65. Aslani H, Miranda E. Probability-based seismic response analysis. Engineering Structures 2005; 27(8): 11511163. DOI: 10.1016/j.engstruct.2005.02.015.

66. Kohrangi M, Bazzurro P, Vamvatsikos D. Vector and scalar IMs in structural response estimation, part II: building demand assessment. Earthquake Spectra 2016; 32(3): 1525-1543. DOI: 10.1193/053115EQS081M.

67. Krawinkler H, Medina R, Alavi B. Seismic drift and ductility demands and their dependence on ground motions. Engineering Structures 2003; 25(5): 637-653. DOI: 10.1016/S0141-0296(02)00174-8.

68. Jalayer F, Cornell CA. A technical framework for probability-based demand and capacity factor design (DCFD) seismic formats. Pacific Earthquake Engineering Research Center; 2004.

69. Jalayer F, Cornell CA. Alternative non-linear demand estimation methods for probability-based seismic assessments. Earthquake Engineering \& Structural Dynamics 2009; 38(8): 951-972. DOI: 10.1002/eqe.876.

70. PEER-TBI. Tall buildings initiative: Guidelines for performance-based seismic design of tall buildings. PEER Berkeley, CA; 2017. 


\section{List of Tables}

Table 1 Steel MRF member sizes for the examined cases.

\begin{tabular}{|c|c|c|c|c|}
\hline Column base & Story & Beam size & Column size & $\begin{array}{l}\text { Doubler plate thickness } \\
\text { (End / Interior) }\end{array}$ \\
\hline \multirow{2}{*}{ Case 1: Conventional fixed } & 2 & W21x93 & W21x111 & $0 / 14 \mathrm{~mm}$ \\
\hline & 1 & W21x62 & W21x111 & $0 / 8 \mathrm{~mm}$ \\
\hline \multirow{2}{*}{ Case 2: Elastic XCB } & 2 & W21x93 & W21x111 & $0 / 14 \mathrm{~mm}$ \\
\hline & 1 & W24x68 & W21x111 & $0 / 11 \mathrm{~mm}$ \\
\hline \multirow{2}{*}{ Case 3: Anchor yielding XCB } & 2 & W21x93 & W24x146 & $0 / 8 \mathrm{~mm}$ \\
\hline & 1 & W21x62 & W24x146 & $0 / 3 \mathrm{~mm}$ \\
\hline
\end{tabular}


Table 2 Comparison of EDP hazard at three representative return periods.

\begin{tabular}{|c|c|c|c|c|c|c|c|c|c|c|c|c|c|}
\hline \multirow{3}{*}{$\begin{array}{l}\text { Return period } \\
\text { (POE in } 50 \mathrm{yrs} \text { ) }\end{array}$} & \multirow{3}{*}{$\begin{array}{l}\text { Annual } \\
\text { rate }\end{array}$} & \multicolumn{6}{|c|}{ Residual story drift ratio (\%) } & \multicolumn{6}{|c|}{ Axial shortening $(\mathrm{mm})$} \\
\hline & & \multicolumn{2}{|c|}{ Fixed base } & \multicolumn{2}{|c|}{ Elastic base } & \multicolumn{2}{|c|}{ Dissipative } & \multicolumn{2}{|c|}{ Fixed base } & \multicolumn{2}{|c|}{ Elastic base } & \multicolumn{2}{|c|}{ Dissipative } \\
\hline & & $\mathrm{SD}$ & LD & SD & LD & SD & LD & $\mathrm{SD}$ & LD & SD & LD & $\mathrm{SD}$ & LD \\
\hline $72(50 \%)$ & 0.0139 & $<0.1$ & $<0.1$ & $<0.1$ & $<0.1$ & $<0.1$ & $<0.1$ & $<0.1$ & $<0.1$ & $<0.1$ & $<0.1$ & 0 & 0 \\
\hline $475(10 \%)$ & 0.0021 & 0.2 & 0.2 & 0.2 & 0.1 & 0.2 & $<0.1$ & 0.5 & 1 & $<0.5$ & $<0.5$ & 0 & 0 \\
\hline $2475(2 \%)$ & 0.0004 & 0.6 & 0.4 & 0.6 & 0.4 & 0.6 & 0.2 & 5 & 15 & 3 & 7 & 0 & 0 \\
\hline
\end{tabular}


List of Figures
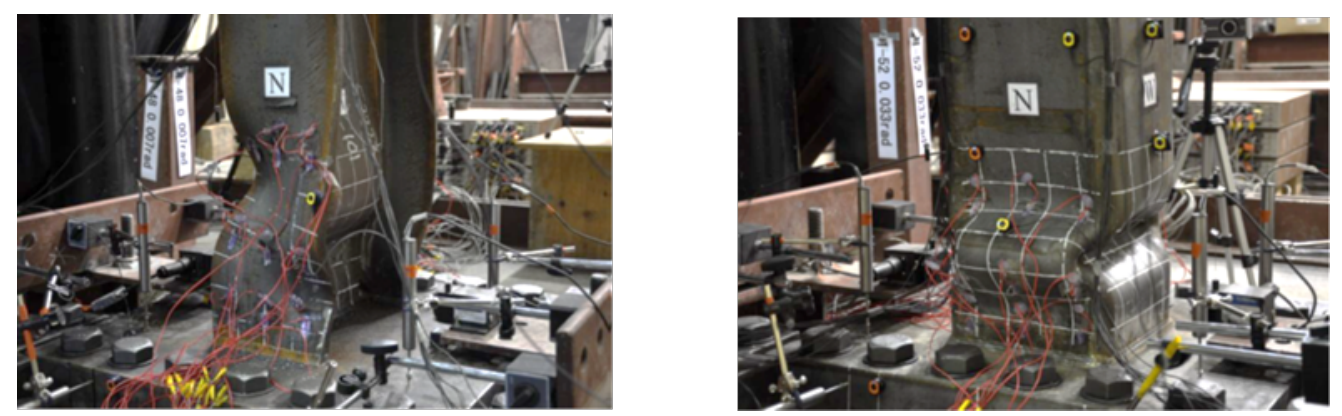

Figure 1. Residual column axial shortening of steel columns: (Left) W14x53 (axial shortening $=55 \mathrm{~mm}$ ) and (Right) HSS 254x9.5 mm (axial shortening $=72 \mathrm{~mm}$ ) (Images were retrieved from [7]). 

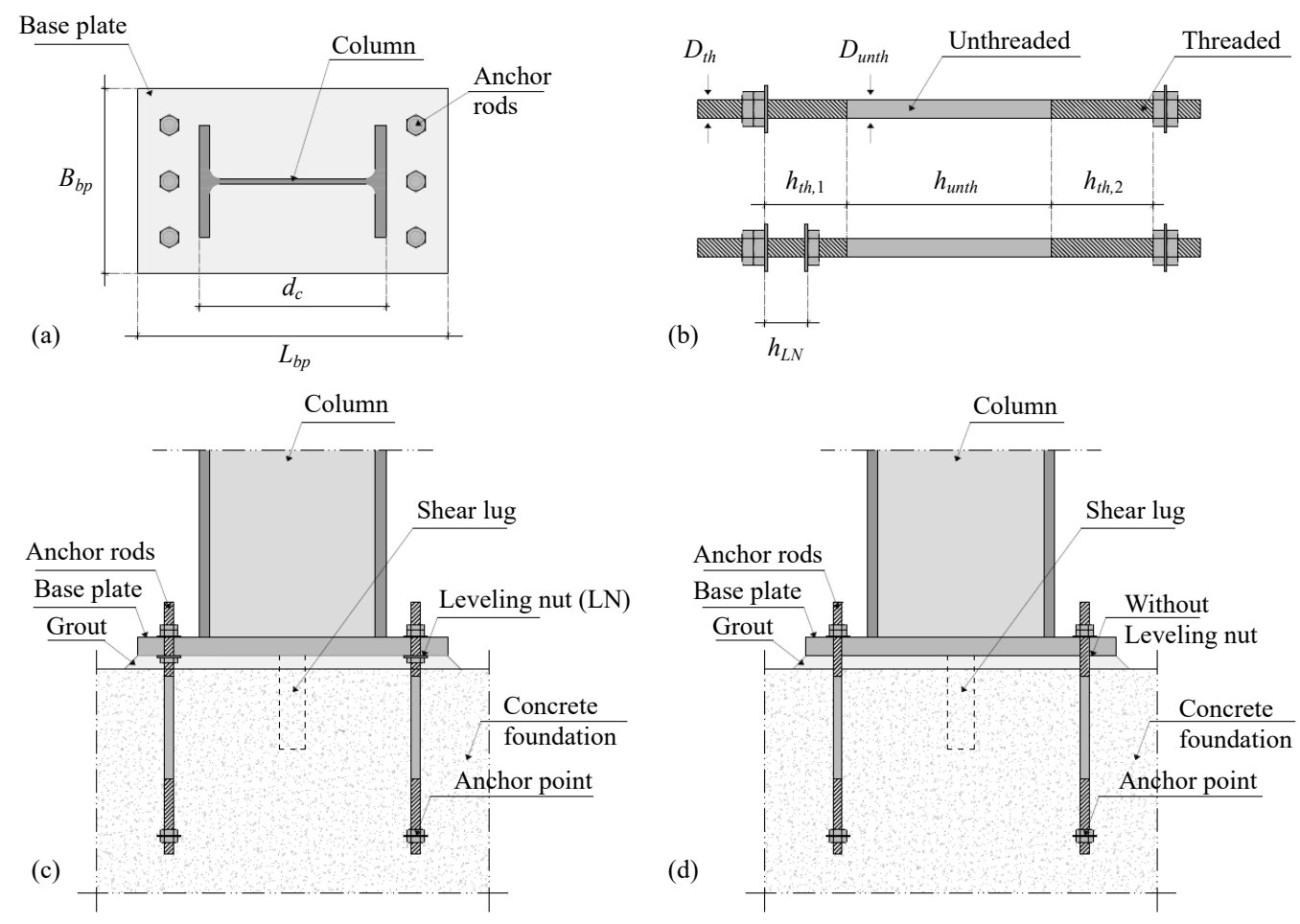

Figure 2. Typical exposed column base connection: (a) Plan view; (b) Anchor rods with/without leveling nuts; (c) Elevation view with leveling nuts; and (d) Elevation view without leveling nuts. 


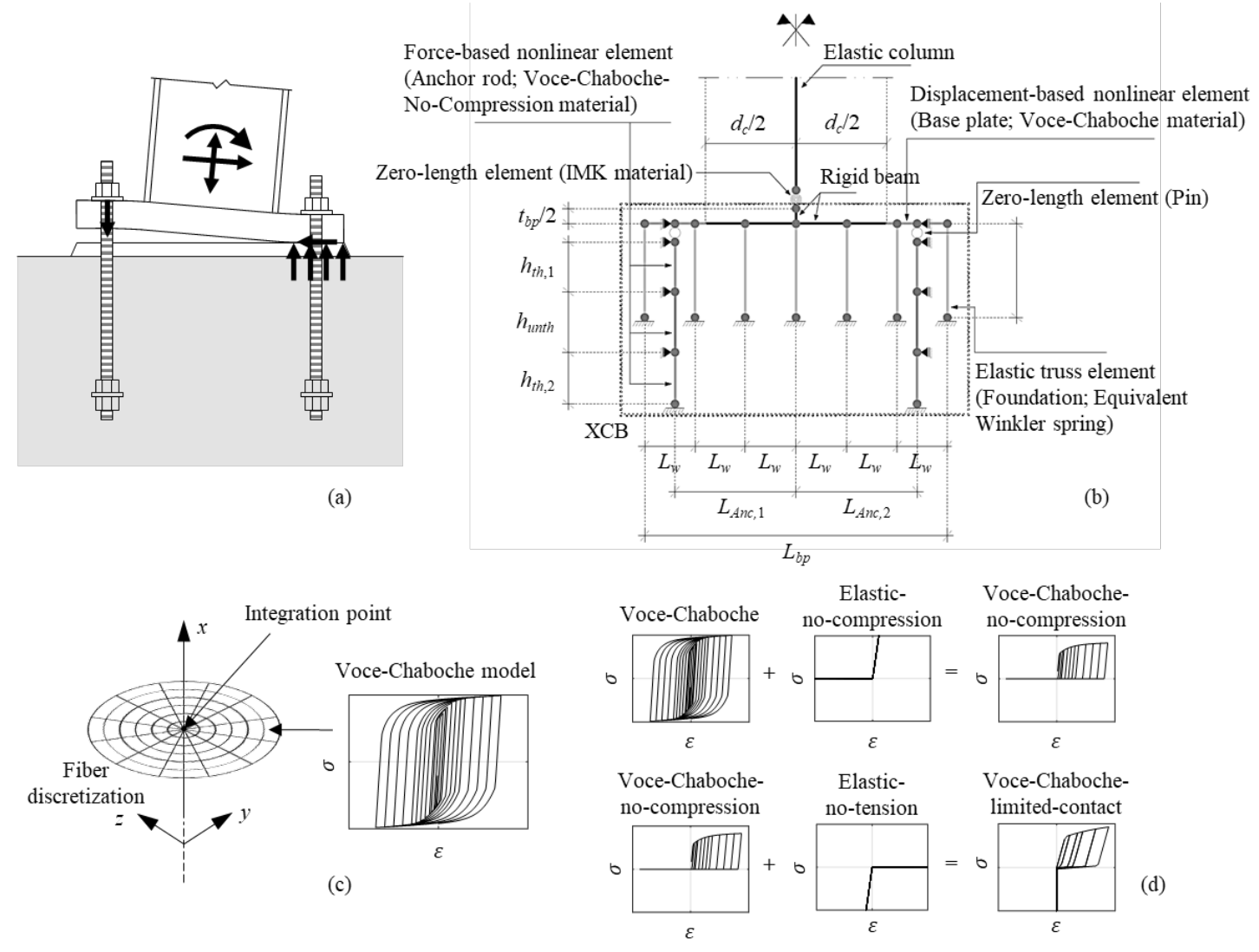

Figure 3. Proposed model for exposed column base connections: (a) deformed shape of an XCB; (b) an overview of the model (in case of no leveling nut); (c) fibers of anchor rods; and (d) material modeling. 

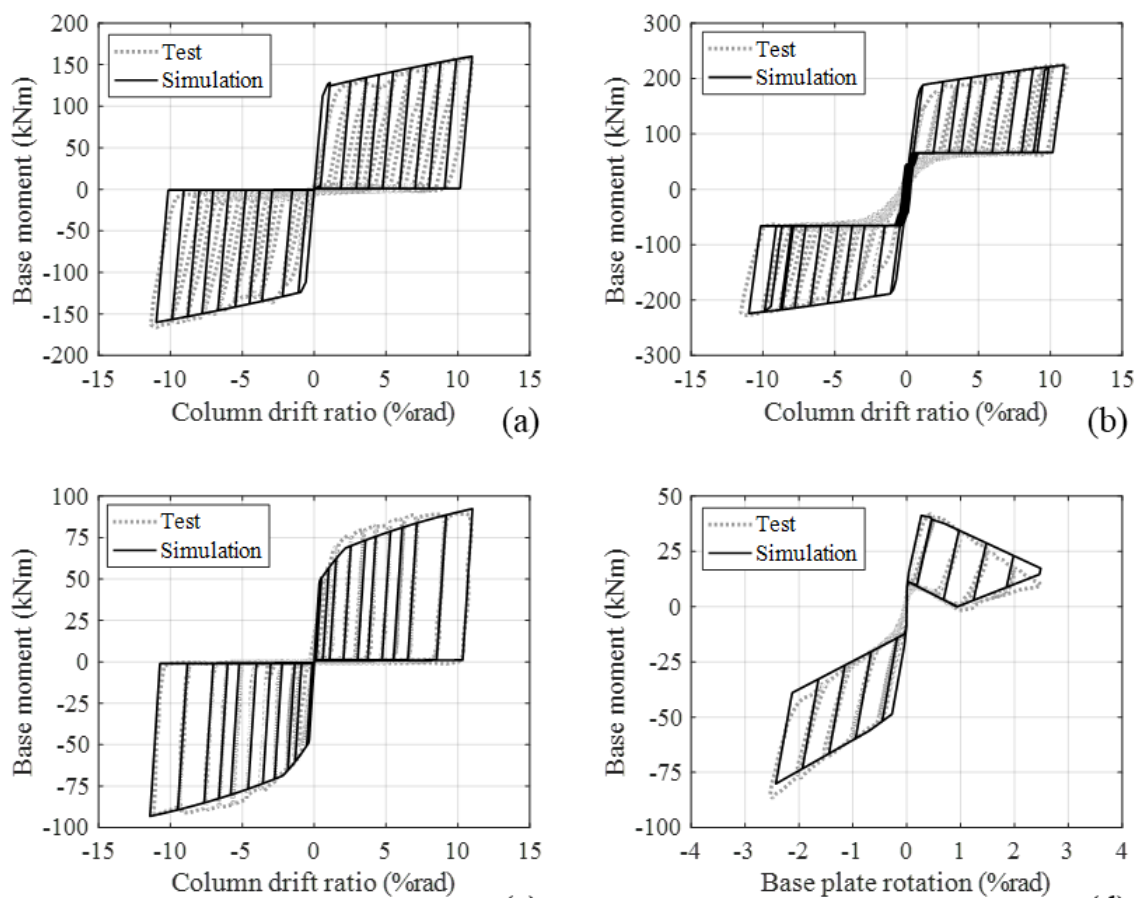

(c)

(d)
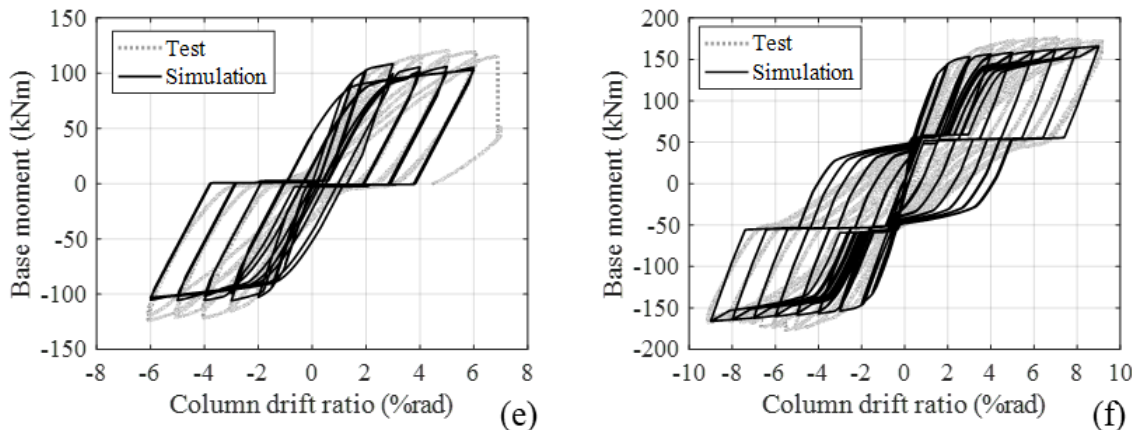

Figure 4. Validations of the developed model for exposed column base connections: (a) Fix-Ab-N=0C; (b) Fix-Ab-N=0.1C (data from [45]); (c) S1S2 (data from [27]); (d) S-Var (data from [24]); (e) specimen 2; and (f) specimen 5 (data from [25]). 

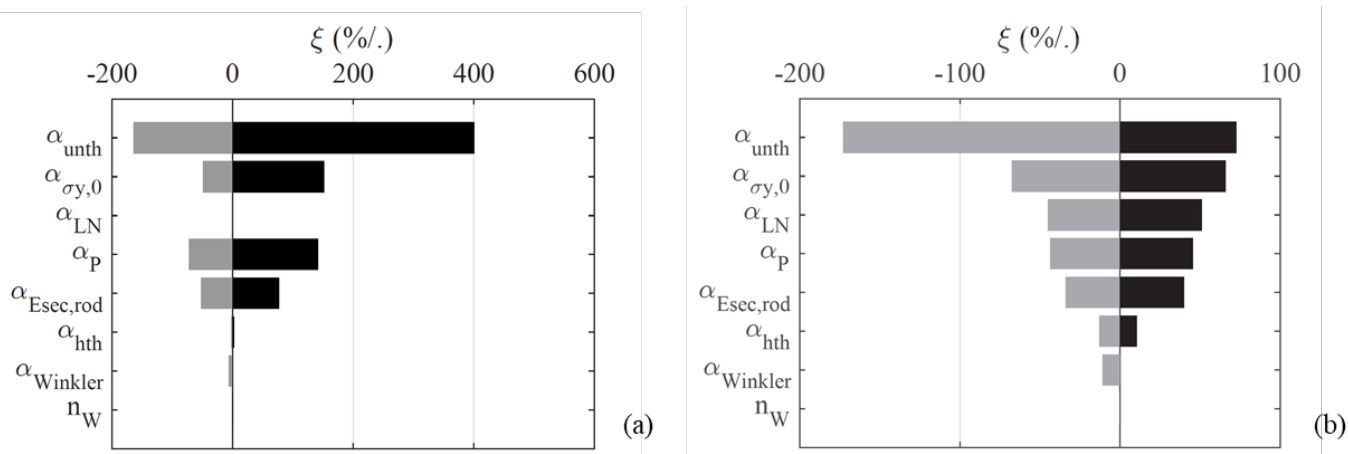

Figure 5. Tornado plot for sensitivity factor $\xi$ : (a) specimen Fix-Ab-N=0.1C (data from [45]) and (b) specimen 5 (data from [25]). 


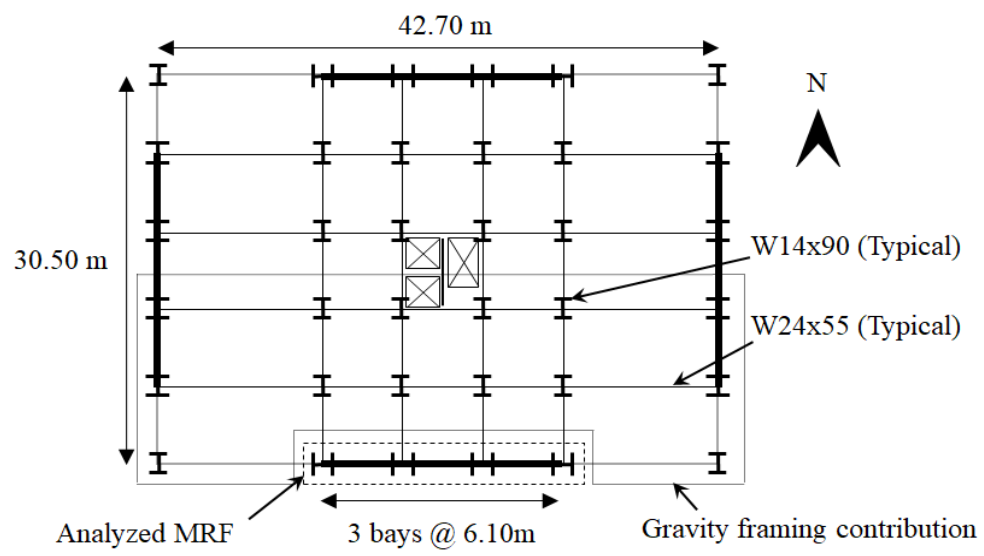

Figure 6. Plan view of the building. 


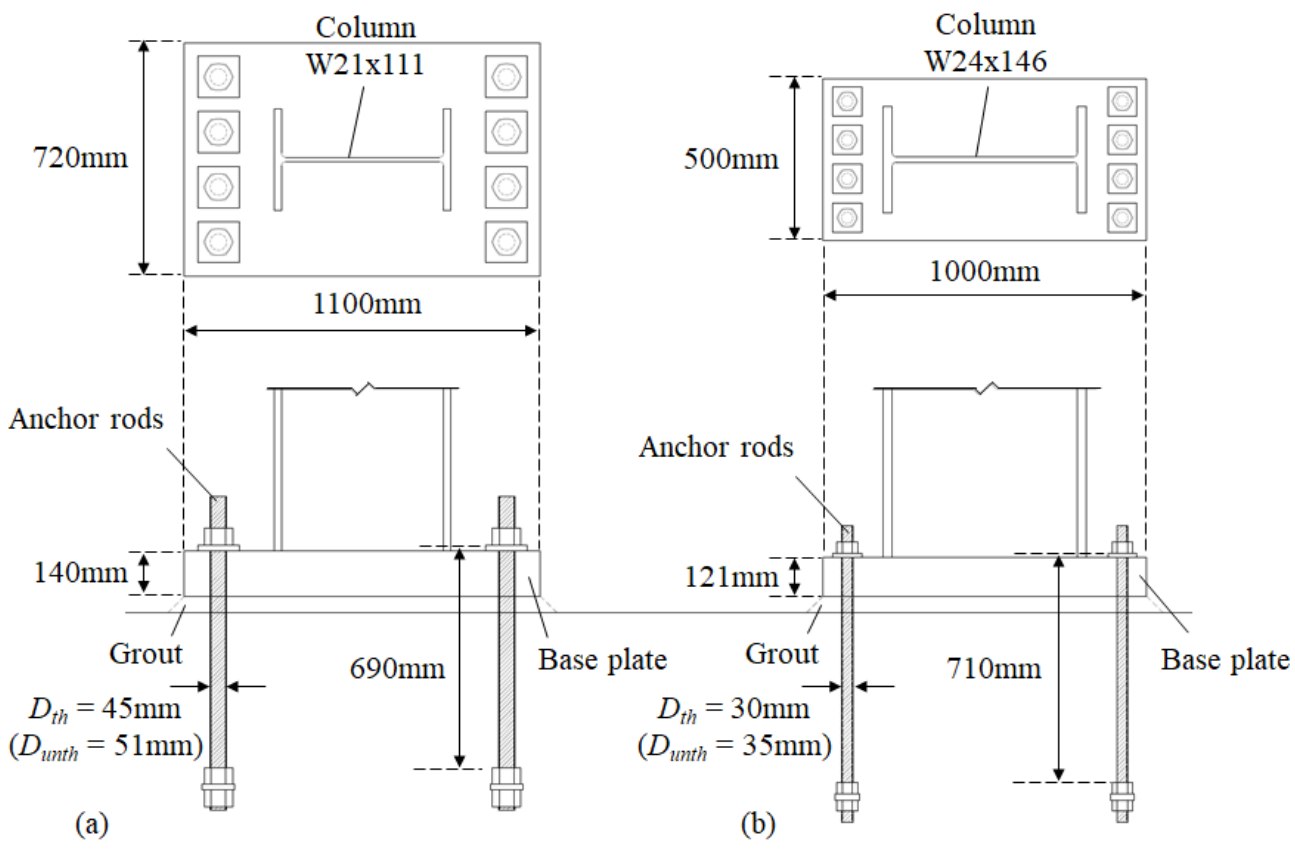

Figure 7. Design of exposed column base connections (a) elastic column bases and (b) anchor yielding dissipative column bases. 


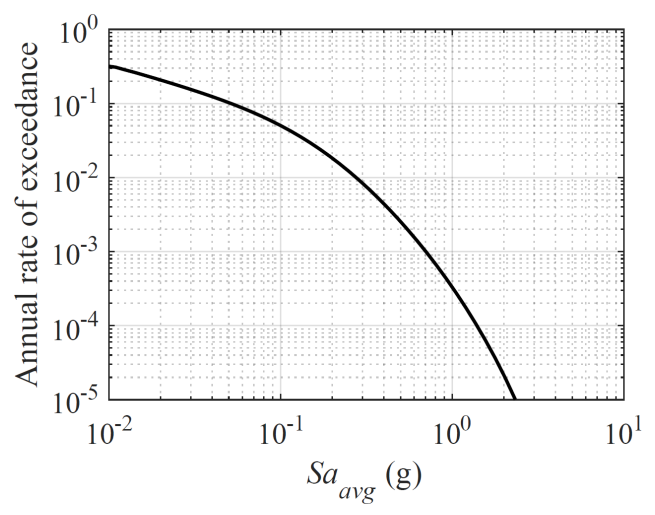

Figure 8. Site-specific $S a_{a v g}$ hazard curve. 

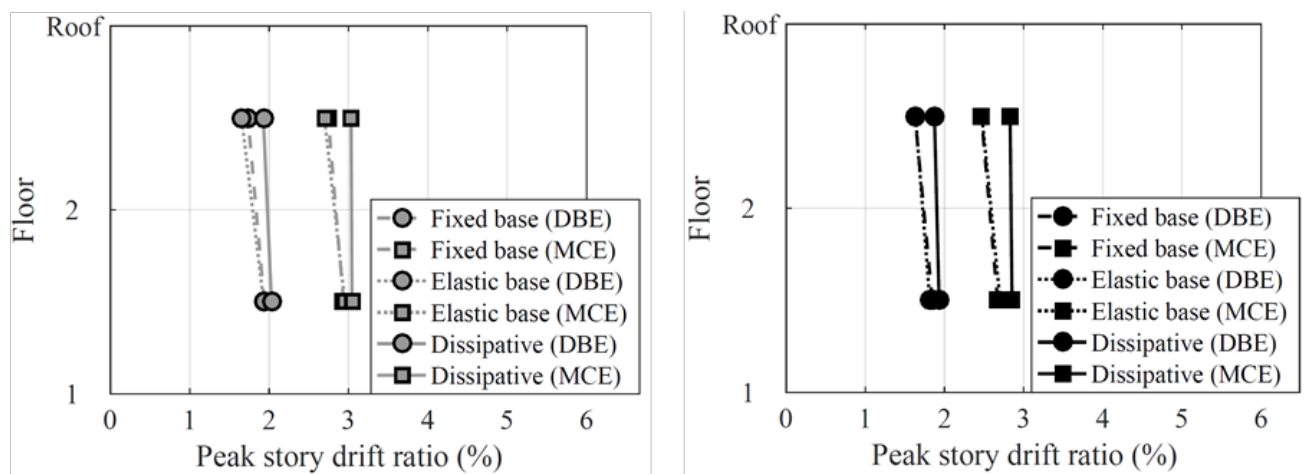

(a)
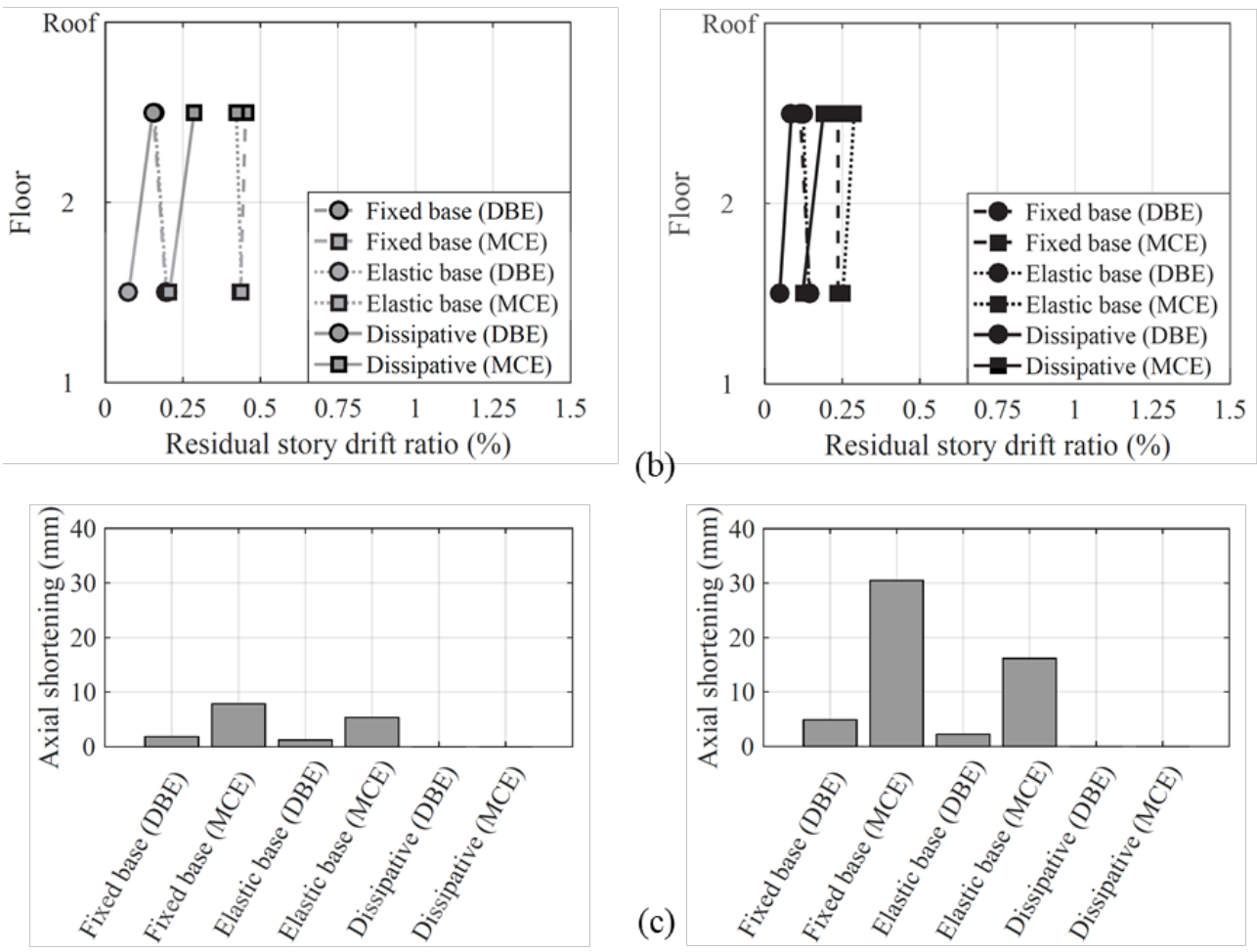

(b)

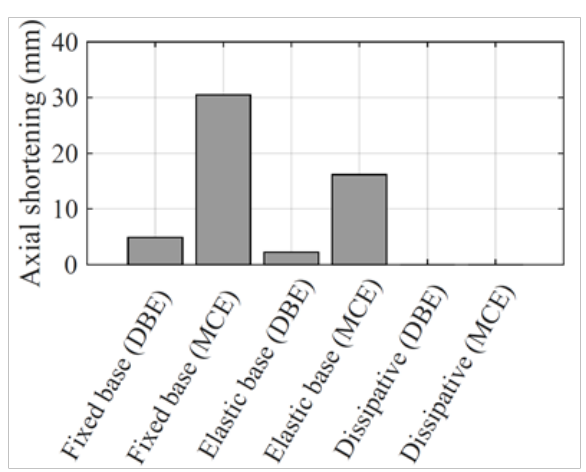

Figure 9. Effect of column base connection type on engineering demand parameters; (a) peak story drift ratio; (b) residual story drift ratio; and (c) column axial shortening. Left: short duration; Right: long duration. 

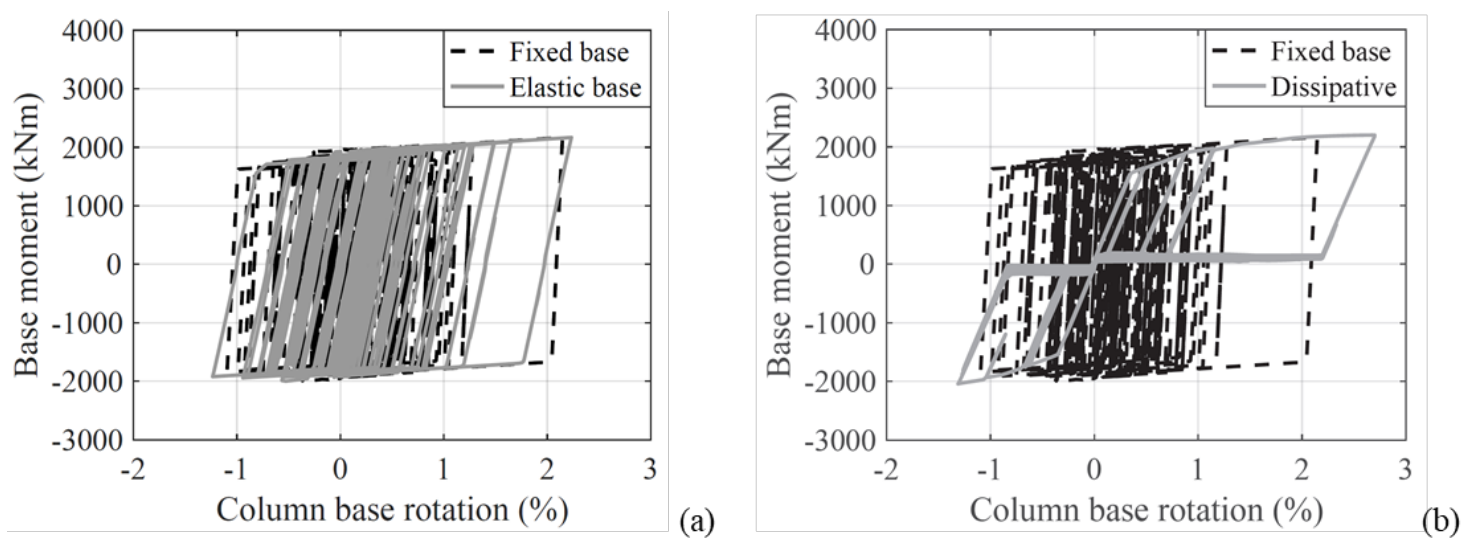

Figure 10. Effect of column base connection type on interior column base moment - rotation for a characteristic case (1974 Lima Peru Earthquake recorded at Arequipa station) scaled at the maximum considered earthquake: (a) ideally fixed versus flexible base and (b) ideally fixed versus dissipative base. 

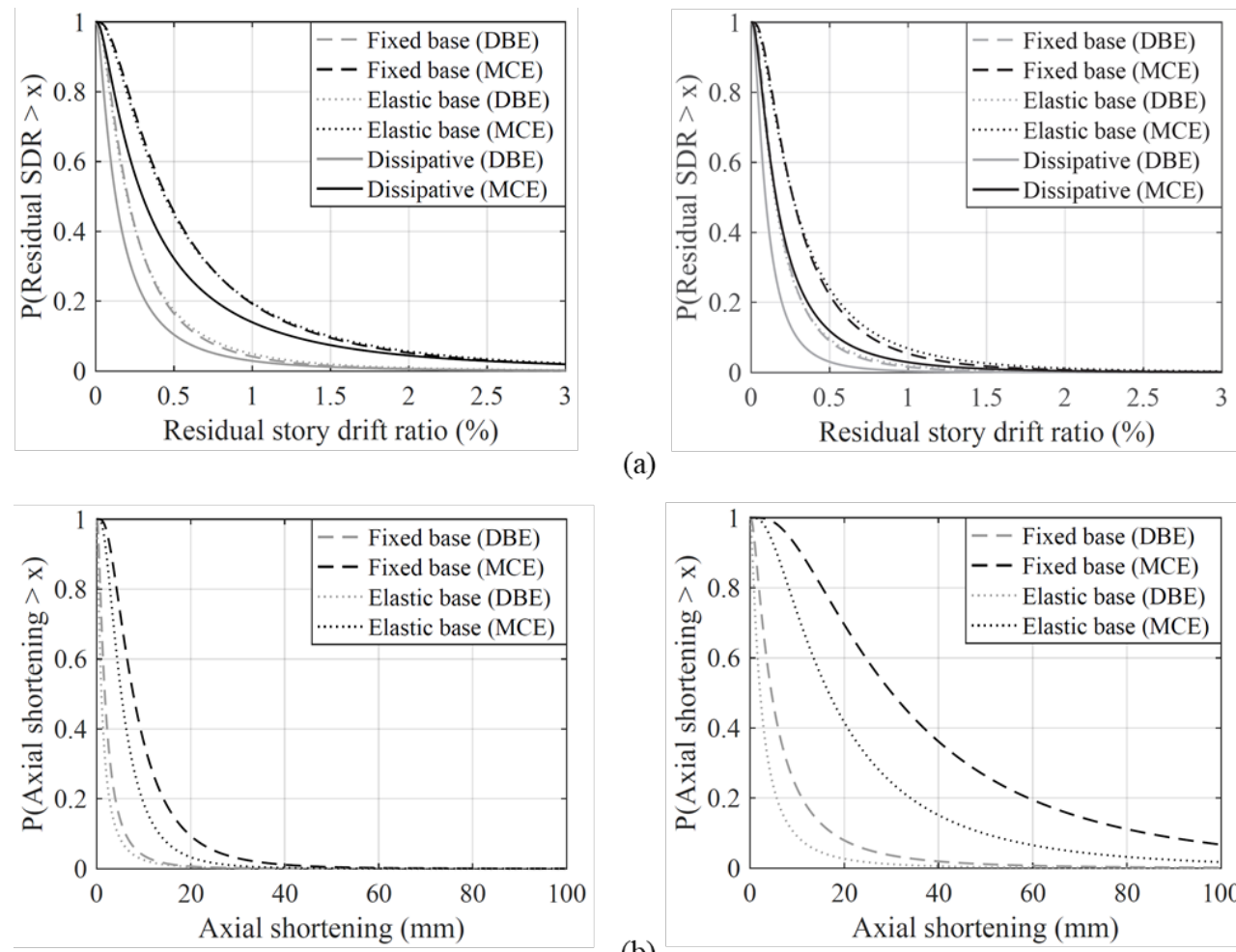

(a)

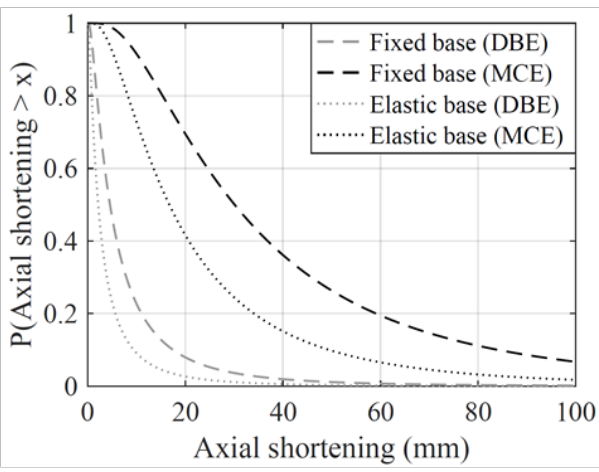

(b)

Figure 11. Exceedance functions for characteristic engineering demand parameters; (a) residual story drift ratios; (b) column axial shortening of the first story interior column. Left: short duration set, Right: long duration set. 

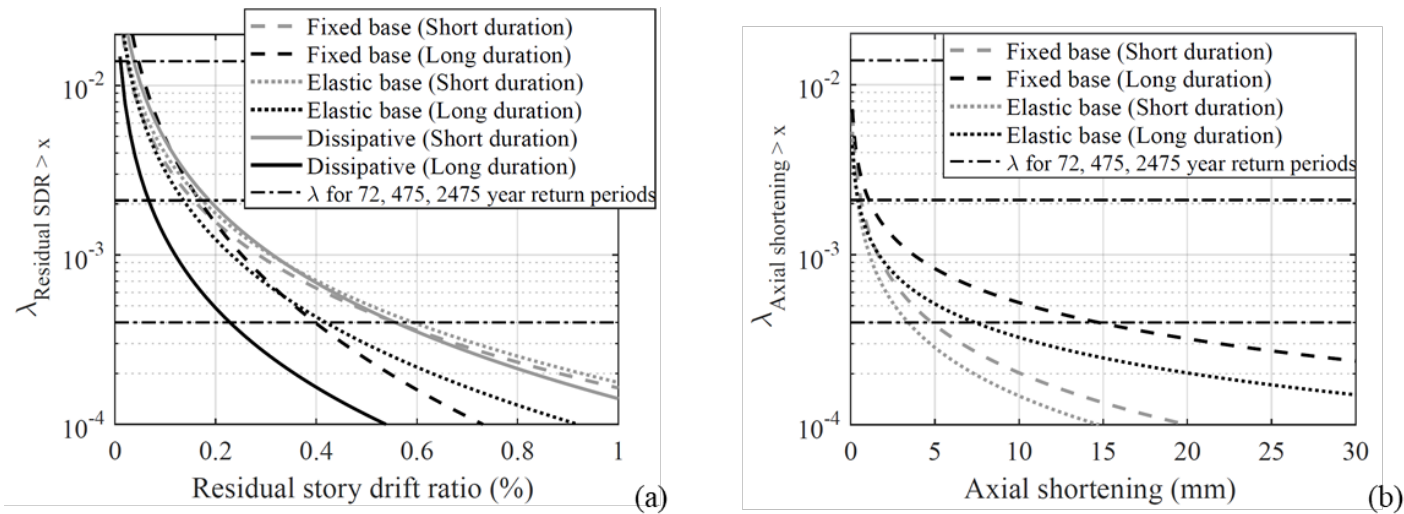

Figure 12. Developed EDP hazard curves for 2-story steel MRF designs: (a) residual story drift ratio and (b) column axial shortening. 
